\title{
EARTHQUAKE RISK MANAGEMENT ON A COMMUNITY LEVEL - A CASE STUDY OF BHAKTAPUR DURBAR SQUARE
}

\author{
Libas Phaiju1, Rameswor Shrestha², Suraj Shah ${ }^{2}$ \\ ${ }^{1}$ Post Graduate Department of Urban Design and Conservation, Khwopa Engineering College \\ ${ }^{2}$ Department of Civil Engineering, Khwopa College of Engineering
}

\begin{abstract}
Earthquake is a natural hazard which when it happens turn out to be disaster that kill thousands of people and cause devastation of cities and villages within 30-60 seconds. Natural disaster may cause large economic impact and impeded socioeconomic development. Virtually the entire population of Nepal is at risk of natural hazards. Earthquake interrupts the proper functioning of the community causing socio-cultural and economic imbalances and losses which results very hard situation to sustain life with available resources. Due to its location on a tectonic active zone Nepal has a long history of earthquake activities of smaller and greater magnitude which are an inevitable part of Kathmandu valley as well. The Statement of problem in research (based on field survey 2067) was about different socio-economic and development activities induced by people or community which made their buildings and places defenceless during natural hazard like earthquake. The research focused on earthquake risk and its management at community level by identifying, analysing and mitigating the vulnerability of the people, place and buildings at Bhaktapur Durbar Square area through physical and social vulnerability studies and was limited tostudy of earthquake risk management through rapid visual assessment and analysis. The study area that lies in the world heritage site is vulnerable to earthquake risk not only due to different socio economic and development activities but also due to inaction from concerned authorities. So; the earthquake risk can be mitigated through community level earthquake risk management as it is the most effective and sustainable.
\end{abstract}

Keywords: Earthquake, community, vulnerable, Community level earthquake risk management, rapid visual assessment analysis

\section{Introduction}

Earthquake affects whole community in its every aspect so it is almost impossible for any agency, or even the government as a whole, to manage all aspects of risk because responsibility for managing earthquake risk is diffused. All organizations and every individual in a community are responsible for managing some aspect of the risk and it is important for community, organizations and residents

*Corresponding author: Libas Phaiju

Post Graduate Department of Urban Design and

Conservation, Khwopa Engineering College, Libali-8,

Bhaktapur

Email: libasphaiju@gmail.com

(Received: 10 $0^{\text {th }}$ Jan 2019 Accepted: 08 ${ }^{\text {th }}$ April 2019) to understand what their responsibilities are so that each community, organization and individual knows beforehand which actions need to be taken, when and by how there are major activities such as Mitigation and Preparedness, Emergency Response and Relief, Rehabilitation and Reconstruction as (Carter, 1991) in earthquake risk management cycle which a community must or should conduct to reduce the impact of the disaster and identifies the groups responsible for implementing above mentioned activities. There are different levels of earthquake risk management like national (central), intermediate (provincial, state or regional) and community (municipality, local government or village) level as (Carter, 1991) but this paper focus on community level earthquake risk management. The paper focuses need of community level earthquake risk management as, after disaster, the 
survived family members and people in the neighbourhoods come first for help and rescue and government bodies may be dysfunction, and civil servant themselves turn victim, in such situation it is unrealistic to depend on civil servant, public services and disaster management specialist rather we prepare ourselves for disaster like earthquake. Thus, having local residents as risk management planners make our community much safer so that each individual protects herself/himself, and further he/she protects his/her families. Community plays a critical role in supporting those who do not have families and those who need special assistance. This paper complements to identify, analyse and mitigate the vulnerability of the buildings and places in the site for earthquake risk by putting judgement on physical and social vulnerability study of the site.

\section{Literature Review}

\subsection{Earthquake Risk Management}

Different steps of earthquake risk management include identification of various risks in the site for earthquake and their analysis through physical and social vulnerability studies followed by preactivities that is mitigate and preparedness for the treat of earthquake risks with frequent monitoring and reviewing of all the steps of earthquake risk management (Fig. 1).

\subsection{Vulnerability Analysis}

Among various vulnerability studies, this research focuses on physical and social vulnerability analysis (Fig.2). Physical vulnerability (Fig.3) study includes the analysis of building types, building condition and building age. Further the building types are categorized into M3RCC, L4RCC, BC and BM with reference to the study done by (JICA, 2002) as the study area mainly consist of such type of buildings. Besides, analysis of floors addition, vertical division, dampness, building story and building use/activities define the building condition.

Similarly, social vulnerability (Fig.4) studies include the analysis of personal attributes like vulnerable group, risk perception and poverty level and also include the vulnerability studies for earthquake risk due to community and institution.

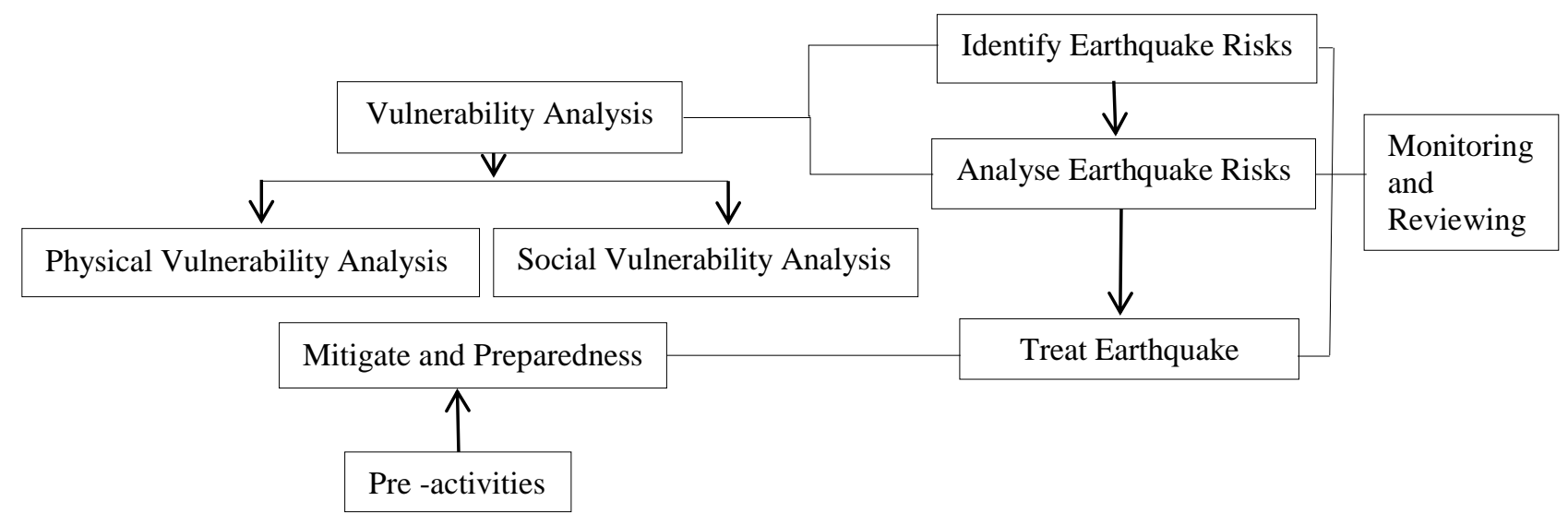

Fig. 1. Different steps of earthquake risk management plan (Salike, 2008) 


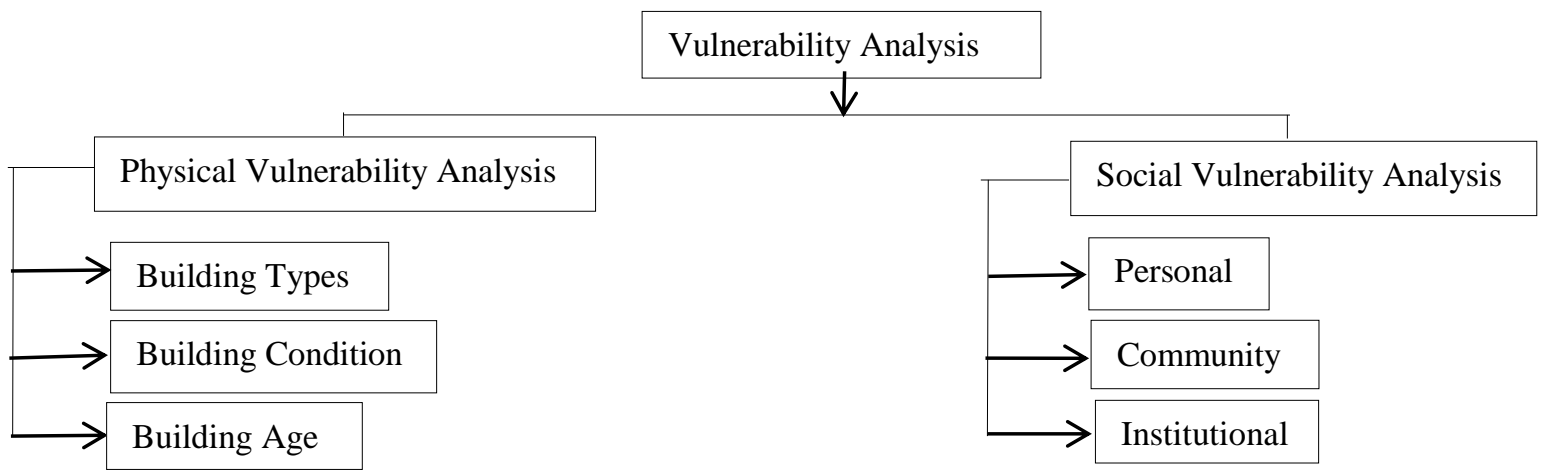

Fig. 2. Types of vulnerability analysis (Carter, 1991)

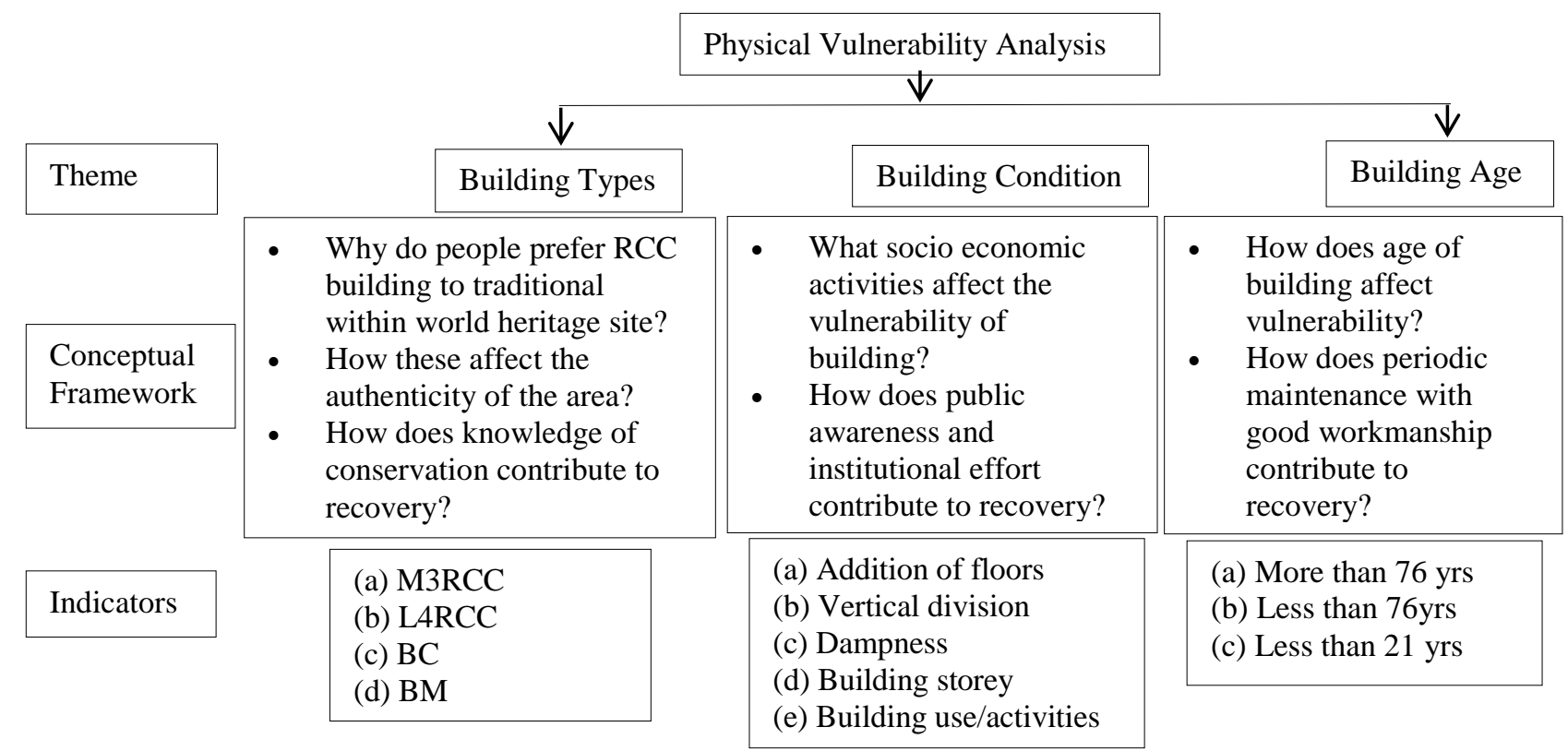

Fig. 3 Framework for physical vulnerability analysis

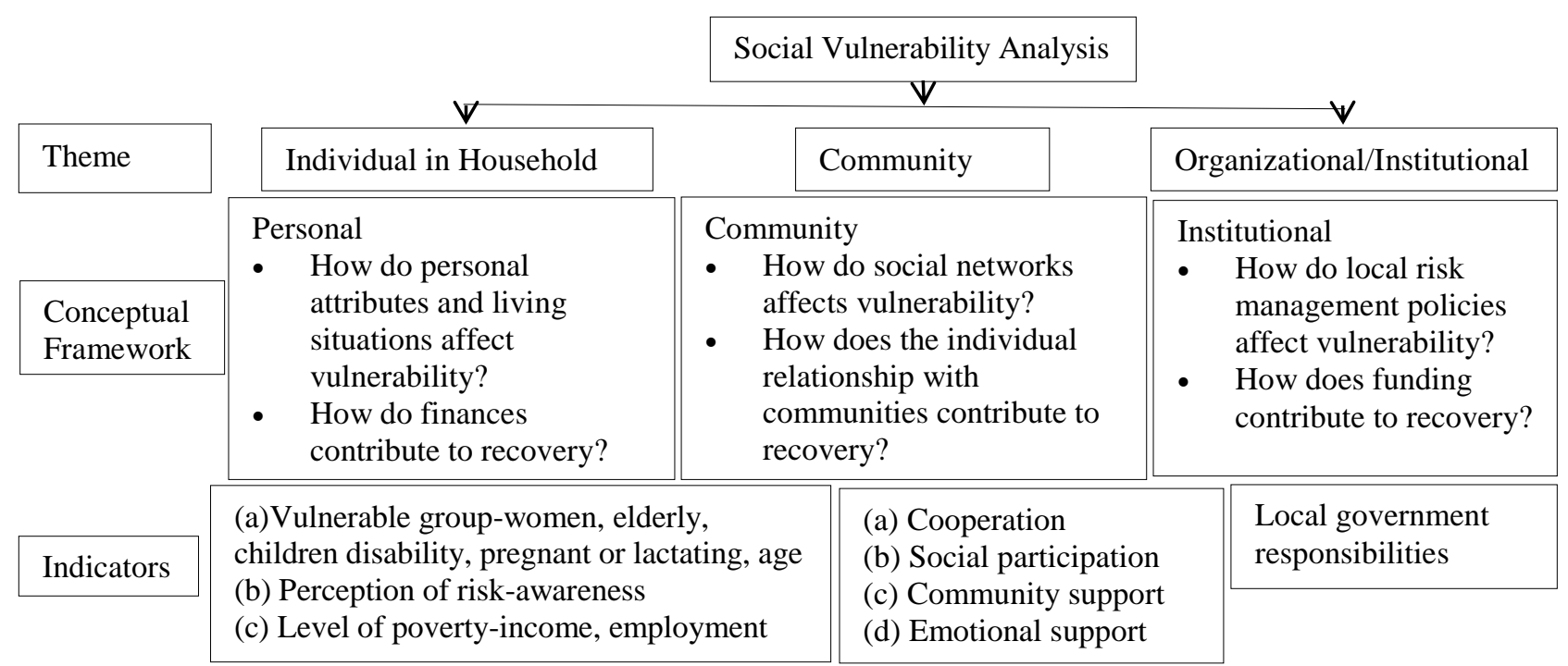

Fig. 4. Framework for social vulnerability analysis (Dwyer et al., 2004) 


\section{Data Collection}

The study focused on earthquake and its impact on the Heritage of Bhaktapur and its urban forms, different level disaster risk management, physical and social vulnerability studies were considered.

Primary data/field data were collected through photographs, visual observation (building condition, storey and uses), measurements (building height, width, courtyard and street width), maps and drawings (updating existing maps and making necessary AutoCAD drawings).

Interview was taken to different personnel involved in relevant organization (Bhaktapur municipality, ward offices, NSET, Khwopa engineering college, Pulchowk Campus, Red Cross Bhaktapur).

Secondary data collection was done from different secondary sources like books, journals, research papers and symposium papers.

\section{Questionnaire Survey}

Questionnaire survey was done to the local residents in the research area. Questions focus on physical and social vulnerability studies which address the different issues like building types, age, uses, construction technology, material, vulnerable groups, and perceptions of different risks and level of poverty.

An analysis of physical vulnerability and social vulnerability were done to analysis the risk of earthquake in a study area and level of risk among various type of physical structure is illustrated.

\section{Physical Vulnerability Analysis 5.1. Building Types and Location}

The study area was focused near Taumadhi Square (Fig. 5). From the structural point of view there are mainly four types of buildings found in the study area viz. more than 3-storey buildings of reinforced concrete with/without masonry wall, RC type of less than four stories with/without masonry wall, brick masonry buildings with cement mortar joints and brick masonry buildings with mud joints (Fig. 6). Most of the existing buildings have problems regarding earthquake resistance as mentioned below.

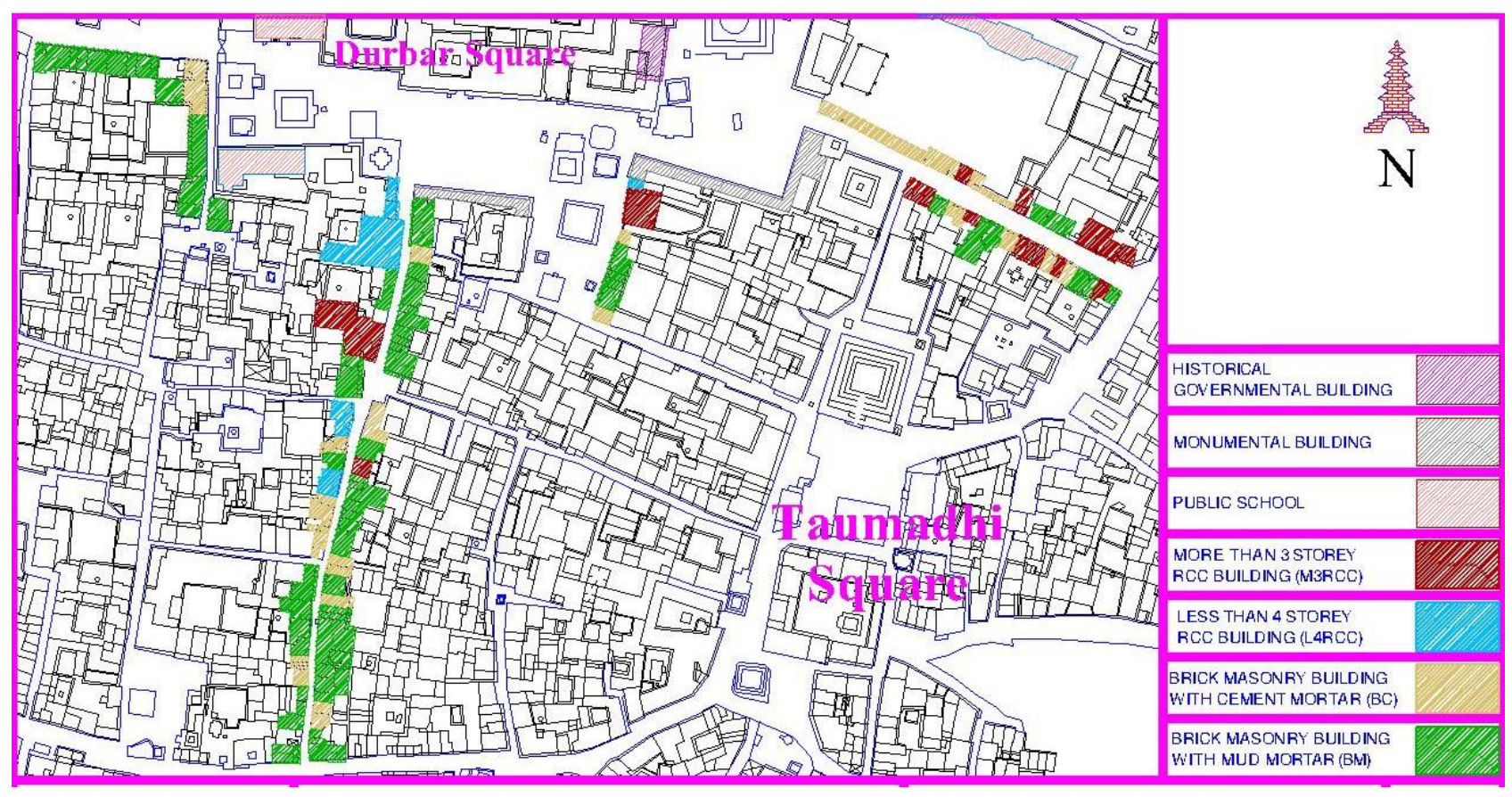

Fig. 5. Building types and location 


\section{Building Types}

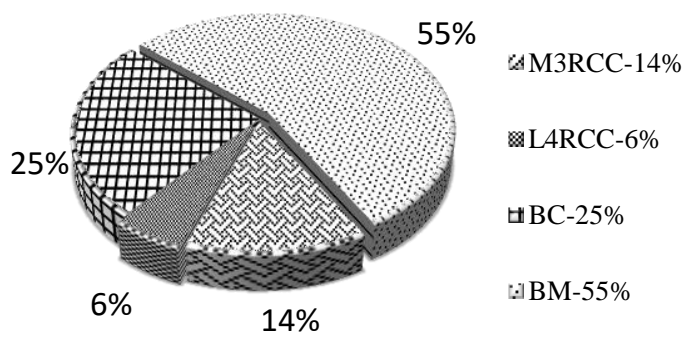

Fig. 6. Building types in study area.

M3RCC -RC type of more than three stories with/without masonry wall

(L4RCC) -RC type of less than four stories with/without masonry wall

(BC)-Brick masonry buildings with cement mortar joints

(BM)-Brick masonry buildings with mud joints

a) More than 3-storey Buildings of Reinforced Concrete with/without Masonry Wall (M3RCC)

\section{Observations:}

There are 14\% (Fig. 6, 15 numbers out of 107) M3RCC buildings (Fig. 7) in the study area. The initial plan such as the size of columns and beams was probably for three-storey buildings. However, existing RCC buildings are extended up to four to six stories, without strengthening the columns and beams. These buildings have strong beam but weak column.
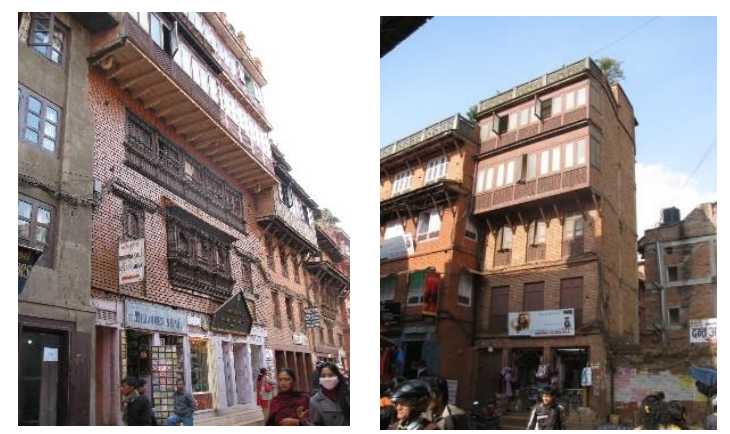

Fig. 7. More than 3-storey buildings of RCC

\section{Analysis}

M3RCC buildings are vulnerable to earthquakes not only due to above mention activities but also due to poor workmanship, absence of site supervision by qualified professional, lack of inspections for quality control, good design and construction practices during any stage of construction by owners, designers, local officials or supervisors.

\section{b) RC Type of Less Than Four Stories with/without Masonry Wall (L4RCC)}
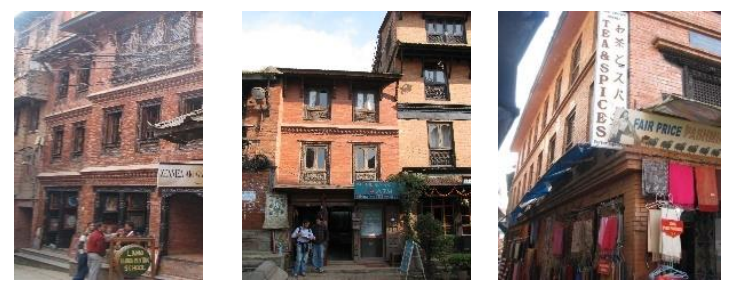

Fig. 8. RC type of less than four stories (L4RCC)

\section{Observations:}

There are only $5.6 \%$ (Fig. 6, 6 numbers out of 107) L4RCC buildings (Fig. 8) in the study area. These L4RCC buildings would have the proper size of columns and beams.

\section{Analysis}

If correctly designed and constructed to the draft $\mathrm{NBC}$, with correct beam depth and reinforcement bars, it would resist an earthquake to some extent. But there are very few numbers of such types of building in the study area. According to the economic conditions of the owners, construction contracts are customarily handled on a personal basis. Quality control problems are likely to occur when owners make their own arrangements for resources and construction materials and pay the workers on a piecemeal basis.

\section{c) Brick Masonry Buildings with Cement Mortar Joints (BC)}

\section{Observations:}

It has been found that there are about 25.23\% (Fig. 6, 27 numbers out of 107) BC buildings (Fig. 9) in 
the study area. This type of building is generally with rigid RC slabs for floors and roof. They are improved in structural strength when compared with brick masonry buildings with mud joints.
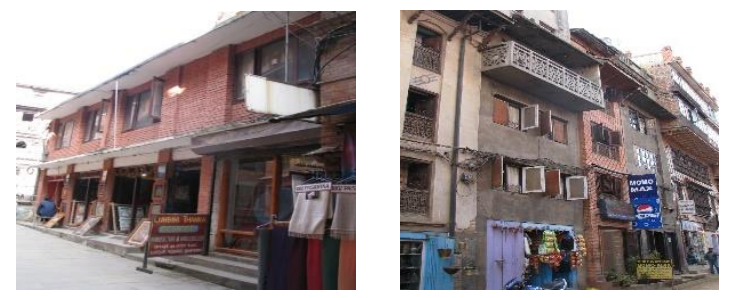

Fig. 9. Brick masonry with cement mortar (BC)

\section{Analysis}

However, they are still poor regarding horizontal rigidity due to poor workmanship and lack of structural consideration regarding the joints between walls, floors and roofs. Although buildings of this type less than four stories constructed with suitable workmanship and good wall balance may see safe, those that are more than four stories are highly vulnerable during a great earthquake. Instead of discouraging this activity, the construction of such building is increasing in the study area. People prefer construction of RCC building to traditional building because of lack of skilled masons or craft persons/workmanship, cost of carvings too expensive, lack of availability of materials like wood/mud, peer pressure, lack of awareness.

\section{d) Brick Masonry Buildings with Mud Joints (BM)}
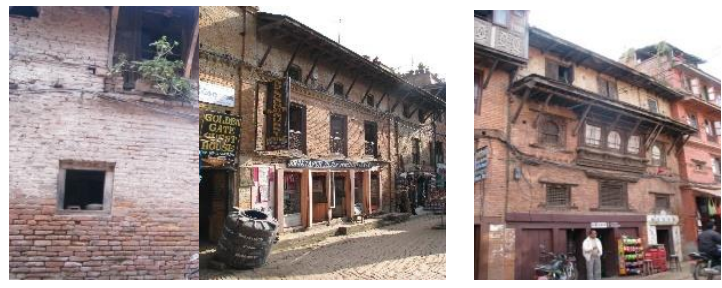

Fig. 10. Brick masonry buildings with mud joints (BM)

\section{Observations}

There are 55.14\% (Fig. 6, 59 numbers out of 107) BM buildings (Fig. 10) which comprise more than half of the buildings in the study area. This category

JScE Vol. 6, April 2019 also consists of traditional Malla and Rana period buildings. These traditional building are made of brick, mud and wood. These buildings have simplicity and symmetry in plan and elevation and have similar building material, detailing and architectural style.

\section{Analysis}

These building (Fig. 10) have very poor horizontal rigidity because of the low bond strength, high absorption of moisture at the mud joints, and the wooden floors and roofs. During a great earthquake, BM buildings of less than three stories or higher seem very fragile not only due to addition of extra floors to obtain space required for increasing family size and vertical division to accommodate individual families but also due to Lack of damp proof course which decreases the lifespan of old buildings.

\subsection{Building Age Observations:}

The age of the buildings (Fig. 11) in the study area has been categorized on the basis of the great earthquake 1934 A.D and earthquake 1988 A.D which severely effected in Kathmandu valley. It has been found that most of the buildings i.e. about 59\% buildings in the study area are of less than 76 years old. They were built after the great earthquake 1934 A.D and there are about $28 \%$ buildings which are of less than 21 years old built after the 1988 A.D earthquake. But still there are $13 \%$ buildings in the study area that are of more than 76 years old i.e. built before the 1934 A.D great earthquake. It is clear that maximum buildings were collapsed during 1934 A.D earthquake. It has been observed that there are major structural cracks in almost all those buildings (13\%) which have survived after $1934 \mathrm{AD}$ great earthquake. $50 \%$ of the buildings which were constructed after1934 AD great earthquake have minor cracks on the walls.

\section{Analysis}

It is not that old buildings are more vulnerable to future earthquake while newly constructed buildings are less vulnerable. Old traditional building maintained frequently with good workmanship and advice from technical expertise may be less Libas Phaiju 25 
vulnerable to earthquake which is proved by the survival of $13 \%$ buildings in the study area built before the 1934 A.D great earthquake whereas the new buildings constructed with poor workmanship and without technical advice from expertise may be more vulnerable to future earthquake.

\section{Building Age}

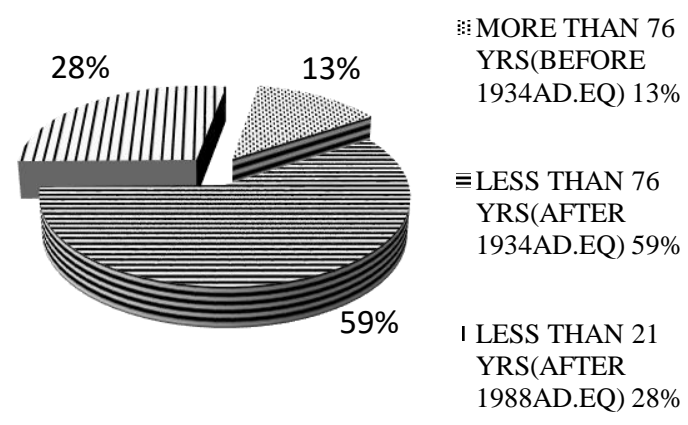

Fig. 11. Building age

\section{Social Vulnerability Analysis 6.1. Personnel/Individual Vulnerable Group}

It is considered that the elderly citizens and children are considered more vulnerable than others during earthquake because of their physical disabilities, lack of mobility to free from collapsing structures, inability to withstand trauma.

\section{a) Gender/Disabilities}

Nearly half women populations (Fig. 12) in the study area are considered more vulnerable than males because of socio cultural norms of the society. Firstly, women are more likely to be indoors in case of earthquake and the attire that they wear hinder them from running because of which building fall on top of them, secondly they are the most responsible for protecting their children due to emotional attachment without bothering herself in times of earthquake and lastly they are most vulnerable to physical violence due to the collapse of social mores with the destruction of traditional community after earthquake. Besides this, from the survey it has been found that nearly half of the female populations are illiterate in the study area; this further more increases JScE Vol. 6, April 2019 the vulnerability of women during earthquake as literate women can only be easily aware and trained in comparison with illiterate one.

Nearly $50 \%$ women populations in the study area are considered more vulnerable than males because of socio cultural norms of the society. Besides this, from the survey it has been found that $44 \%$ female population (Fig. 13) and $26 \%$ of male populations (Fig. 14) were illiterate in the study area; this further more increases the vulnerability of women during earthquake.

\section{Gender/Disabilities}

$\checkmark$ MEN-46.51\%

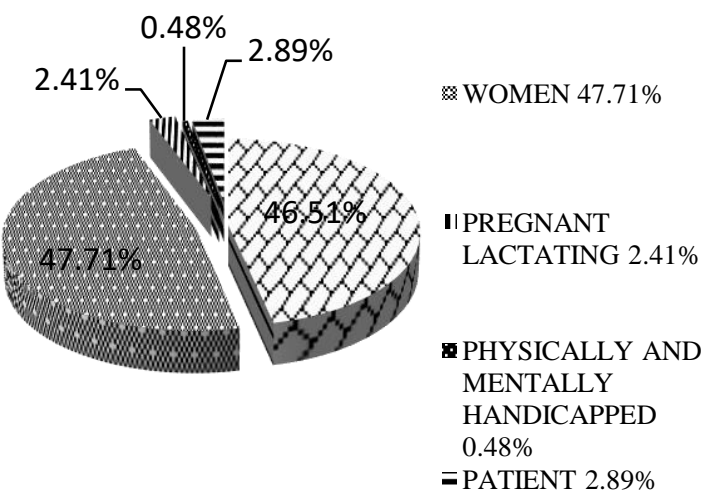

Fig. 12. Gender/Physical disabilities

\section{Women Education Level}

I BELOW SLC $28 \%$

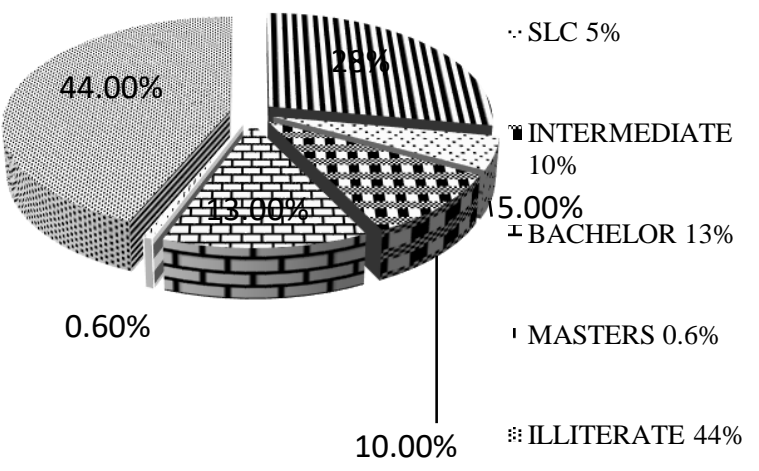

Fig. 13. Education level of women 


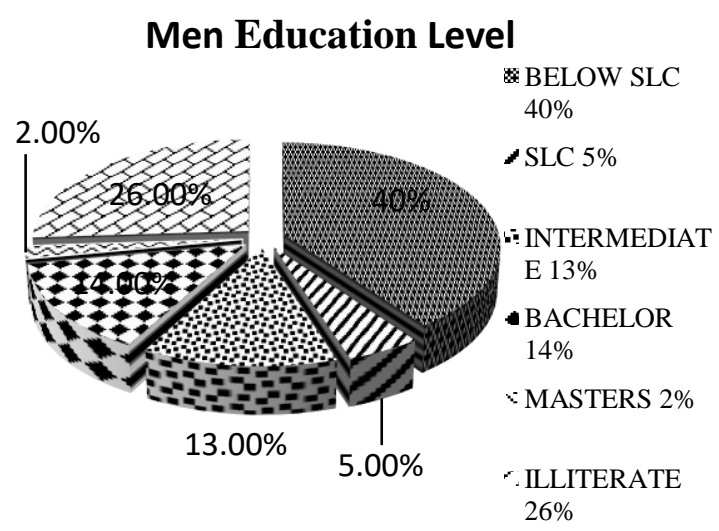

Fig. 14. Education level of men

\section{b) Municipality Support}

It is clear that almost all the people want technical support from municipality rather than loan and subsidies to make their house safer against earthquake. The study area lies in the world heritage site (preserved monument sub zone of cultural heritage conservation zone). Technical advice from municipality with free of cost during renovation of traditional building, helps to make the people's building safer against earthquake and conserve the town. Though municipality has provision of giving subsidies to construct new building within the heritage site but there isn't any provision in case of renovation of old buildings (Fig. 15).

\section{Help from Municipality}

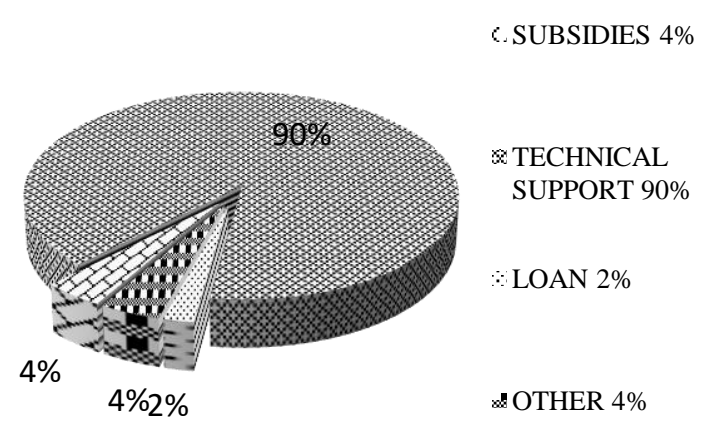

Fig. 15. Support from municipality

\section{c) Rely for the Support in Disaster}

During the survey $60 \%$ hope for support from relatives in case of disaster whereas $24 \%$ expect government support, $14 \%$ local community support and only $2 \%$ rely on Guthi system (Fig. 16). Almost all people are associated with their Guthi system but the people do not rely on it for help during disaster though it is the institution which offer agricultural land-based financing. Guthi can be alternate source of financing, food and sheltering during earthquake. It can also serve as institution for community level disaster management thus it has to be revitalized and strengthen.

\section{Rely for Support in Disaster}

× RELATIVE $60 \%$

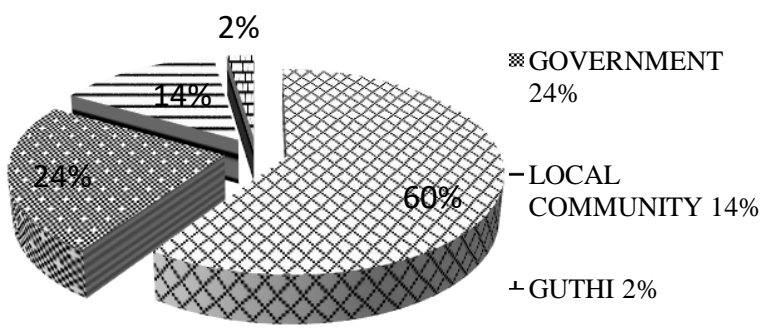

Fig. 16. Relay of support in disaster

\section{d) Household Monthly Income}

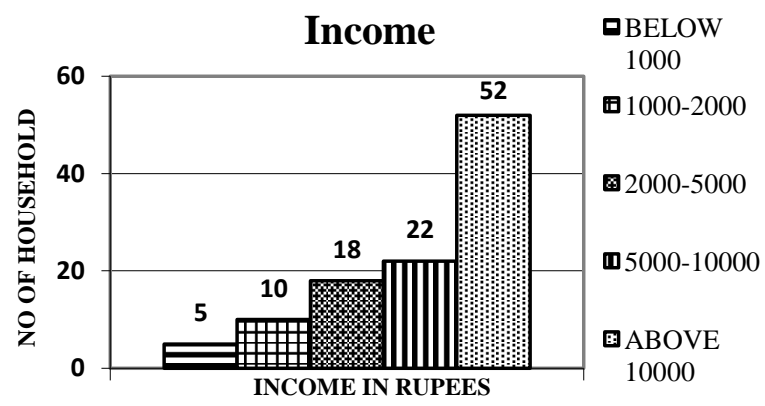

Fig. 17. House hold monthly income

During the survey, it has been found that about $48 \%$ of household's monthly income exceeds 10000 while 20\% have income between 5000-10000, Similarly, $17 \%$ household income range between 2000-5000, and $10 \%$ have income between 10002000 where 5\% households have income below 1000 (Fig. 17). It is clear from the above data that more than 50\% household are not capable to expend 
for strengthening their houses even if technical support is given by the local government to make their houses and town safer against earthquake and psychological impacts. In other words, people of lower socioeconomic status experience higher levels of risk perception as they are poor with less technical ideas; more over these groups tend to worry more about the loss of their homes to earthquakes than higher income groups. Besides, income is related to earthquake preparedness because preparedness increases steadily with income levels as low-income people are incapable of strengthening their homes and also adopting some costly earthquake mitigation measures.

\subsection{Community}

It has been observed that courtyards and open spaces of the study area have been encroaching with incompatible uses by the community. Moreover, community has no concern about the renovation and reconstruction of ruined old buildings in the study area. As already stated above, it has been found that almost all the people of the study area have Guthi system which is created by offering private property, cash or kind including landed property for the sake of sustaining worship in temples, maintaining the public rest houses and performing several socio religious functions. Guthi being the social organization can be the best alternate source for community reliance for shelter and food during natural calamity like earthquake.

\section{Conclusion}

Earthquake, an unavoidable part of the valley is unpredictable and occurs without warning, disrupting the functioning of the society or community causing great socio-cultural and economic losses which is irreplaceable and very difficult to cope. Though the study area, Bhaktapur durbar square lies in the world heritage site having outstanding universal value and representing master piece of human creative genius is vulnerable to earthquake not only due to different socio cultural and economic activities induced by people, society and community but also due to inaction of related authorities, institution and organization.
Thus, the people and place have to be made safer against earthquake through awareness programme, community education and training, enforcement of rules and regulations by institution and organization, financial and technical support, coordination between different authorities, invention and research of new technology compatible to traditional architecture, integrating earthquake resistant into building bylaws, regulation and permit. Though there are different levels of disaster management in Nepal, they have focused more on post disaster response and recovery rather than disaster preparedness. This paper suggests that for mitigation of earthquake risk in community level mandatory compliance of Building code/bylaws is a must. Other pre-requirements are unity among members of community, social strengthening, economic prosperity, and most importantly awareness programme.

\section{References}

[1] Carter, W. N. (1991). Disaster management, a disaster manager's handbook.

[2] Dwyer, A., Zoppou, C., Nielsen, O., Day, S. and Roberts, S. (2004). Quantifying Social Vulnerability: A methodology for identifying those at risk to natural hazards.

[3] ICCROM, IUCN, ICOMOS, and UNESCO WH center. (2008). How to develop disaster risk management plans for world heritage properties, A resource manual.

[4] Japan International Cooperation Agency, and the Ministry of Home Affairs of Nepal. (2002). The study on Earthquake Disaster Mitigation in the Kathmandu Valley, Kingdom of Nepal, Volume I, II, and III.

[5] Jigyasu, R. Developing the ICCROM Training Kit on "Risk Preparedness for Cultural Heritage" - Scope, Features and Challenges.

[6] Salike, I. P. (2008) Risk management of cultural heritage on local level, a case study of Bhaktapur Nepal.

[7] UNESCO. (2006). Participatory workshop on urbanization and community based disaster management 